Archived version from NCDOCKS Institutional Repository http://libres.uncg.edu/ir/asu/

\title{
Appalachìn
}

$\overline{B \text { O O N E, N O R T H C A O L I N A }}$

\section{Remote Sensing And Geomorphometry For Studying Relief Production In High Mountains}

\author{
By: Michael P. Bishop, John F. Shroder, Jr., and J.D. Colby
}

\begin{abstract}
Mountain topography is the result of highly scale-dependent interactions involving climatic, tectonic, and surface processes. No complete understanding of the geodynamics of mountain building and topographic evolution yet exists, although numerous conceptual and physical models indicate that surficial erosion plays a significant role. Mapping and assessing landforms and erosion in mountain environments is essential in order to understand landscape denudation and complex feedback mechanisms. This requires the development and evaluation of new approaches in remote sensing and geomorphometry. The research herein evaluates the problem of topographic normalization of satellite imagery and demonstrates the use of terrain analysis using a digital elevation model (DEM) to evaluate the relief structure of the landscape in the western Himalaya. We specifically evaluated the Cosine-correction and Minnaert-correction methods to reduce spectral variation in imagery caused by the topography. Semivariogram analyses of the topography were used to examine the relationships between relief and surface processes. Remote-sensing results indicate that the Minnaert-correction method can be used to reduce the "topographic effect" in satellite imagery for mapping, although extreme radiance values are the result of not accounting for the diffuse-skylight and adjacent-terrain irradiance. Geomorphometry results indicate that river incision and glaciation can generate extreme relief, although the greatest mesoscale relief is produced by glaciation at high altitudes. At intermediate altitudes, warm-based glaciation was found to decrease relief. Our results indicate that glaciation can have a differential influence on the relief structure of the landscape.

Collectively, our results indicate that scale-dependent analysis of the topography is required to address radiation transfer issues and the polygenetic nature of landscape denudation and relief production.
\end{abstract}

Bishop, M.P., Shroder Jr., J.F., and Colby, J.D. (2003). Remote Sensing and Geomorphometry for Studying Relief Production in High Mountains. Geomorphology, 55: 345-361. Published by Elsevier (ISSN: 1872-695X).

Publisher version of record available at: https://www.sciencedirect.com/science/article/pii/

S0169555X03001491?via\%3Dihub 
Bishop, M.P., Shroder Jr., J.F., and Colby, J.D. (2003). Remote Sensing and Geomorphometry for Studying Relief Production in High Mountains. Geomorphology, 55: 345-361. Published by Elsevier (ISSN: 1872-695X).

\title{
Remote sensing and geomorphometry for studying relief production in high mountains
}

\author{
Michael P. Bishop, John F. Shroder, Jr., and Jeffery D. Colby
}

\begin{abstract}
Mountain topography is the result of highly scale-dependent interactions involving climatic, tectonic, and surface processes. No complete understanding of the geodynamics of mountain building and topographic evolution yet exists, although numerous conceptual and physical models indicate that surficial erosion plays a significant role. Mapping and assessing landforms and erosion in mountain environments is essential in order to understand landscape denudation and complex feedback mechanisms. This requires the development and evaluation of new approaches in remote sensing and geomorphometry. The research herein evaluates the problem of topographic normalization of satellite imagery and demonstrates the use of terrain analysis using a digital elevation model (DEM) to evaluate the relief structure of the landscape in the western Himalaya. We specifically evaluated the Cosine-correction and Minnaertcorrection methods to reduce spectral variation in imagery caused by the topography. Semivariogram analyses of the topography were used to examine the relationships between relief and surface processes. Remote-sensing results indicate that the Minnaert-correction method can be used to reduce the "topographic effect" in satellite imagery for mapping, although extreme radiance values are the result of not accounting for the diffuse-skylight and adjacent-terrain irradiance. Geomorphometry results indicate that river incision and glaciation can generate extreme relief, although the greatest mesoscale relief is produced by glaciation at high altitudes. At intermediate altitudes, warm-based glaciation was found to decrease relief. Our results indicate that glaciation can have a differential influence on the relief structure of the landscape. Collectively, our results indicate that scale-dependent analysis of the topography is required to address radiation transfer issues and the polygenetic nature of landscape denudation and relief production.
\end{abstract}




\section{INTRODUCTION}

Globally significant interactions between climate, surface processes, and tectonics have recently been proposed to explain climate change and mountain building [Molnar and England, 1990, Raymo and Ruddiman, 1992 and Avouac and Burov, 1996]. This hypothesis suggests that enhanced glaciation should result in increased erosion, uplift and relief production. Numerous studies have examined mountain topography to understand the influence of surface processes on relief production (e.g., [Burbank et al., 1996, Brozovik et al., 1997, Bishop and Shroder, 2000, Bishop et al., 2002, Brocklehurst, 2002. S.H. Brocklehurst, Glacial erosion and relief production in the Eastern Sierra Nevada, California. Geomorphology 42 (2002), pp. 1-24. Article | PDF (1095 K) | View Record in Scopus | Cited By in Scopus (72)Brocklehurst, 2002 and Finlayson et al., 2002]), although the influence of glaciation on the relief structure of the landscape is complex and not always accounted for in conceptual models and numerical simulations.

Understanding the differential influence of glaciation on relief production will require research to address the issues of polygenetic topographic evolution, identifying and mapping the operational scale of surface processes, identifying and mapping the operational scale at which landscape denudation affects the macroscale tectonic influx of mass [Bishop and Shroder, 2000 and Bishop et al., 2002], and developing and evaluating new parameterizations for erosion modeling. Some of these issues can be investigated using satellite imagery and digital elevation models (DEMs), as valuable spatial and temporal information can be extracted. Producing reliable geomorphological information from satellite data, however, is difficult because numerous environmental factors such as the atmosphere, topography, and land cover control the irradiant and radiant flux. Other factors such as solar and sensor geometry must also be taken into consideration, such that the magnitude of the surface-radiant flux varies in all directions (anisotropic reflectance). Consequently, satellite imagery must be radiometrically calibrated to account for these factors so that variations in image radiance are representative of biophysical variations of the landscape. An operational solution to this problem has yet to materialize [Bishop and Colby, 2002].

Analysis of the topography, however, is increasingly being used to study surface processes and erosion due to the availability of DEMs from remote sensing. Geoscientists routinely examine the first-order statistical nature of the topography to study relief production. The nature of the problem, however, requires that "issues of scale" be accounted for when characterizing geomorphometric properties and conducting spatial analysis [Shroder and Bishop, 1998 and Bishop and Shroder, 2000]. Furthermore, an important goal is to accurately characterize the organization of the topography in relation to erosion and internal forcings so that statistical metrics/indices or model parameters can be calibrated with measured erosion rates [Howard, 1996]. Consequently, new spatial analysis procedures and models need to be developed and evaluated [Small, 1999 and Bishop and Shroder, 2000].

The purpose of this research was to examine various issues associated with information extraction from satellite imagery and DEMs. We evaluate radiometric calibration procedures and analysis of the topography at Nanga Parbat, in northern Pakistan, to better understand 
radiation-transfer processes and relief production. Specifically, our objectives were to (i) compare the Cosine- and Minnaert-correction models for radiometric calibration of satellite imagery; and (ii) examine the mesocale relief structure of the landscape on the north side of Nanga Parbat.

\section{STUDY AREA}

The Nanga Parbat summit $(8125 \mathrm{~m})$ is part of a knife-edged ridge that extends in a NE-SW direction (Fig. 1). Structurally, the Nanga Parbat massif occurs within transpressive shear zones that are spatially and temporally linked with youthful granite plutonism. The NW Raikot and SE Stak fault shear zones define a crustal-scale, antiformal pop-up structure that resembles an asymmetrically upward moving, cork-like plug that began 12-10 Ma [Schneider et al., 1999. D.A. Schneider, M.A. Edwards, W.S.F. Kidd, M.A. Khan, L. Seeber and P.K. Zeitler, Tectonics of Nanga Parbat, western Himalaya: synkinematic plutonism within the doubly vergent shear zones of a crustal-scale pop-up structure. Geology 27 (1999), pp. 999-1002. Full Text via CrossRef | View Record in Scopus | Cited By in Scopus (51)Schneider et al., 1999].

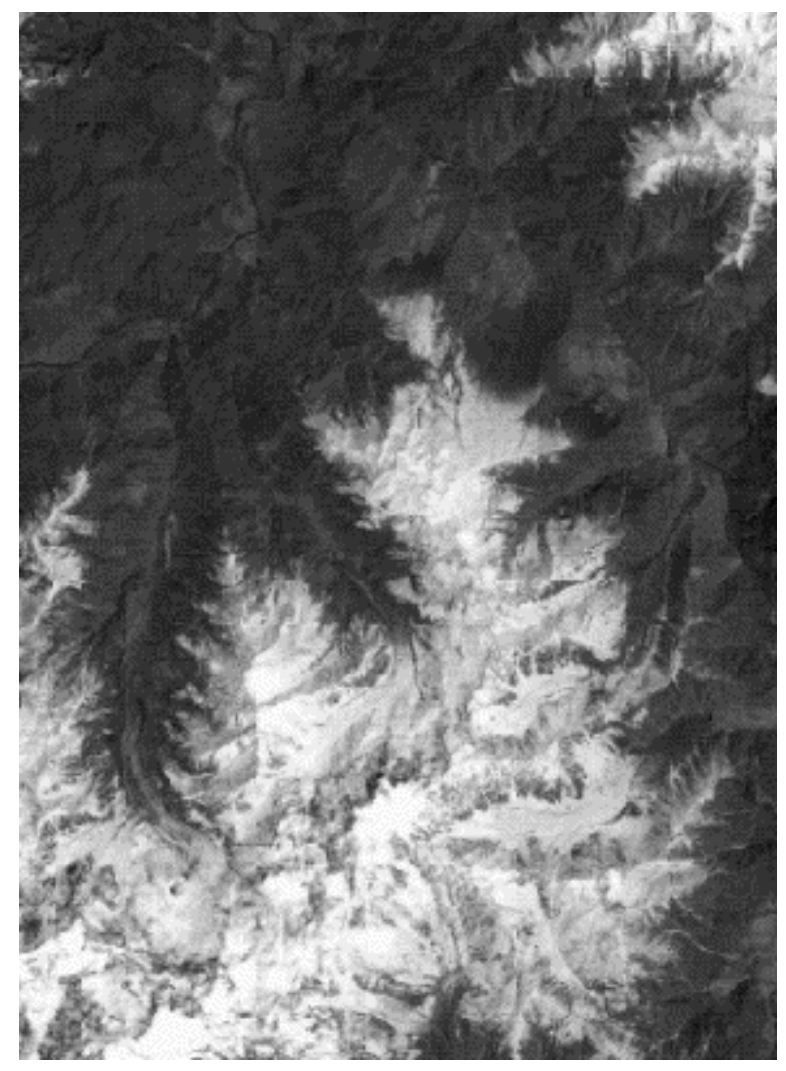

Fig. 1. SPOT 3 ortho-rectified NIR image of Nanga Parbat, in Northern Pakistan. The Indus and Astor Rivers are located in the NW and NE portions of the image respectively. The knife-edged Nanga Parbat ridge is oriented in a NE-SW direction and is visible in the lower part of the image. 
[Shroder and Bishop, 2000. J.F. Shroder, Jr. and M.P. Bishop, Unroofing of the Nanga Parbat Himalaya. In: M.A. Khan, P.J. Treloar, M.P. Searle and M.Q. Jan, Editors, Tectonics of the Nanga Parbat Syntaxis and the Western Himalaya (2000), pp. 163-179. Full Text via CrossRef | View Record in Scopus | Cited By in Scopus (18)Shroder and Bishop, 2000] noted that the initial denudation cascade at Nanga Parbat probably began 11 Ma when the Indus River was captured from its west-flowing position on Kohistan rocks overlying Nanga Parbat gneisses and diverted abruptly south across what is now the north and west sides of the massif. This time is also approximately coincident with possible structural disturbance of the drainage and the onset of the first monsoonal precipitation in the region, which suggest further causation for the capture. Subsequently from the late Miocene to early-middle Pleistocene, the accelerated erosion of the Nanga Parbat region has left little record of the processes involved.

The development of glacial and fluvial drainages that dominate the Nanga Parbat massif is the result of complex geologic evolution reflecting a sequence of temporally linked drainage types (Table 1). Beginning with superposition from the Kohistan cover sequence, the newly captured and rapidly downcutting Indus River seems to have initiated uplift of the massif. This newly recognized combination of fluvial superposition followed by focused tectonism leads to a new understanding of supercedance in which capture of a superposed stream caused antecedant uplift across the course of the master Indus and Astor rivers. The rising supercedant massif then caused consequent radial drainages from its flanks, one of which seems to have eventually captured the upper Astor-Rupal and resulted in annular encirclement of half the range. Eventually, the mountain rose high enough and the climate grew cold enough so that glaciers developed and glacial-drainage diversions would have been common. It is unlikely, however, that records exist of all these geomorphic events since the late Miocene that would enable detailed reconstructions of topographic evolution of the massif. Instead, interpretation of uplift progress and landform development must be based upon examination of the existing landscape and geomorphometric properties that reflect the polygenetic nature of topographic evolution. 
Table 1. Sequence of geomorphic events over the past 12 Ma leading to the existing drainage network on Nanga Parbat

1. - Paleo-Indus River flowing WNW on cover volcanic rocks of Kohistan sequence that overlie gneisses of Indian Plate rocks.

- NW-flowing, paleo-Astor River is tributary to the Indus well NW of its present junction and also flowing on cover rocks.

- Ancestral SW-flowing Nagri River eroding headward into Kohistan cover rocks to eventually capture upper Indus River.

2. Capture of Indus River and superposition of paleo-Indus and paleo-Astor down to expose Indian plate rocks.

- Incipient uplift zone established between Nanga Parbat and Haramosh because of erosional unloading.

3. - Superposition+antecedance=supercedant drainage established.

- Accelerating uplift of Nanga Parbat massif.

- Development of consequent radial drainage on massif.

4. - Subsequent, radial drainage development.

- The Rupal-upper Astor River system erodes further as a subsequent annular stream with apparent conformity to metamorphic isograds, perhaps in response to updoming.

- Some brittle fault displacement of Indus River along Raikot Fault.

- Waxing and waning Pleistocene glaciations and possible diversions cause further minor development of drainages on Nanga Parbat.

5. - Holocene development of the modern drainage net.

- Contimued Raikot Fault displacement of Indus River.

[Bishop et al., 1998b] and [Bishop and Shroder, 2000] used satellite imagery to examine erosion and deposition features at Nanga Parbat to identify geomorphic events, and to better understand the role of surface processes in the denudation cascade. They initially found that reliable information produced from satellite imagery is dependent upon reducing spectral variation caused by the topography and land cover. Furthermore, they indicated that more advanced forms of analysis and modeling are required to produce useful information.

In general, investigators have attempted to correct for the influence of topography on upward radiance by accounting for the nature of surface reflectance (Lambertian or non-Lambertian) and the local topographic conditions [Colby, 1991, Ekstrand, 1996 and Colby and Keating, 1998]. Semi-empirical approaches include Cosine-correction [Smith et al., 1980], Minnaertcorrection [Colby, 1991], the c-correction model [Teillet et al., 1982], and other empirical corrections that make use of a DEM to account for the local illumination conditions for each pixel. These models have been widely applied given their relative simplicity and ease of implementation. They have not been appropriately evaluated in rugged terrain such as the Himalayas.

Research findings indicate that these approaches may work only for a given range of topographic conditions [Smith et al., 1980 and Richter, 1997]. The Cosine- and Minnaertcorrection procedures are frequently used and [Bishop et al., 1998a. M.P. Bishop, J.F. Shroder, Jr., B.L. Hickman and L. Copland, Scale dependent analysis of satellite imagery for characterization of glacier surfaces in the Karakoram Himalaya. Geomorphology 21 (1998), pp. 217-232. Article | PDF (1370 K) | View Record in Scopus | Cited By in Scopus (25)Bishop et 
al., 1998a] found that the Minneart-correction procedure has the potential to be used to study the problem, provided that issues associated with computation and topography are addressed.

Topographic analysis of the Nanga Parbat massif has been conducted to characterize the hypsometry, slope distributions, and first-order relief. [Burbank et al., 1996] concluded that landsliding was primarily responsible for the relief production in the western Himalaya, while [Brozovik et al., 1997] concluded that glaciation limits the production of relief there. Subsequent analyses by [Bishop and Shroder, 2000] and [Bishop et al., 2002] indicated that glaciation has had a significant influence on the landscape and that glaciation plays a significant role in relief production in the Nanga Parbat Himalaya.

\section{METHODOLOGY}

\section{Digital elevation model}

A SPOT 3 panchromatic stereo-pair was acquired on 27 October 1996 and 28 October 1996. A DEM was generated by SPOT Data using the imagery and the stereo-autocorrelation method. Ground control points were obtained from a 1:50,000 topographic map. This approach requires the accurate identification of a pixel in each stereo-pair image that represents the same ground location. The stereo-autocorrelation method requires adequate spectral variation to enable correlation and registration of pixels. Sensor radiometric resolution and highly reflective features such as snow and ice can cause spectral saturation in images, and cast shadows can also cause a significant reduction in spectral variation thereby causing correlation failure.

Topographic map coverage was used to construct the topography at the summit where spectral saturation did occur. This area was extremely small and was not included in our topographic analysis for assessing relief. The ground control points were used to ensure quality control. The resulting DEM exhibited a measurement resolution of $20 \mathrm{~m}$ with a vertical accuracy of $\pm 8-12 \mathrm{~m}$.

\section{Image preprocessing}

Satellite imagery in mountainous terrain must be geometrically and radiometrically calibrated to account for geometric error, sensor system effects, and relief displacement [Chavez, 1996. P.S. Chavez, Jr., Image-based atmospheric corrections-revisited and improved. Photogrammetric Engineering and Remote Sensing 629 (1996), pp. 1025-1036. View Record in Scopus | Cited By in Scopus (406)Chavez, 1996 and Bishop et al., 1998a]. SPOT 3 multispectral data were ortho-rectified using the DEM. SPOT Data produced an ortho-rectified panchromatic image for the Nanga Parbat area using map control [1:50,000 German topographic map by [Finsterwalder, 1936]]. The multispectral imagery were rectified using control points that could easily be identified in the multispectral imagery and ortho-rectified panchromatic imagery. The total root mean squared error was $5.0 \mathrm{~m}$, based on the use of 20 control points.

The satellite imagery were radiometrically calibrated using SPOT's calibration coefficients. Radiometric calibration was achieved using the following equation: 


$$
L_{\lambda}=\frac{\mathrm{DN}}{\alpha_{\lambda}}
$$

where $L_{\lambda}$ is the radiance in $\mathrm{W} \mathrm{m}^{-2} \mathrm{sr}^{-1} \mu \mathrm{m}^{-1}$, DN represents the digital number (0-255), and $\alpha_{\lambda}$ represents SPOT's absolute calibration coefficient. Atmospheric correction procedures were not applied to correct for the additive path-radiance component, given the high altitude of the study area.

\section{Anisotropic-reflectance correction}

The extreme relief and complex topography at Nanga Parbat produces high and low, spatialfrequency, spectral variation in satellite images. We evaluated the Cosine-correction method, which assumes that surface reflectance is isotropic (reflectance is equal in all directions). Research indicates that this assumption is not valid in mountain terrain as the topography and land cover cause anisotropic reflectance (magnitude of radiance varies with direction) [Smith et al., 1980 and Hugli and Frei, 1983]. This procedure accounts for the local topographic conditions that influence the direct solar irradiance. It is based upon the use of the cosine of the incidence angle (i), which is proportional to the direct solar irradiance such that

$\cos i=\cos \theta_{\mathrm{s}} \cos \beta_{\mathrm{t}}+\sin \theta_{\mathrm{s}} \sin \beta_{t} \cos \left(\varphi_{\mathrm{t}}-\varphi_{\mathrm{s}}\right)$

where $\theta_{\mathrm{s}}$ is the solar zenith angle, $\beta_{\mathrm{t}}$ is the slope angle of the terrain, $\varphi_{\mathrm{s}}$ is the solar azimuth angle, and $\varphi_{\mathrm{t}}$ is the slope aspect angle of the terrain. The Cosine-correction method is computed as

$$
L_{\lambda}^{n}=\frac{L_{\lambda}}{\cos i}
$$

where $L_{\lambda}{ }^{n}$ represents normalized radiance resulting from the correction procedure, and $L_{\lambda}$ represents the radiance values from Eq. (1). This method has been found to be useful, given high solar elevation angles and low slope angles [Smith et al., 1980 and Ekstrand, 1996].

We also evaluated the Minnaert-correction procedure using two different implementations. This procedure was implemented using the general backwards radiance-correction procedure described by [Colby, 1991]:

$$
L_{\lambda}{ }^{n}=\left(L_{\lambda} \cos e\right) /\left(\cos ^{k} i \cos ^{k} e\right)
$$

where $e$ is the excitant angle $\left(e=\beta_{t}\right)$ and $k$ is the Minnaert constant that ranges from $0.0-1.0$. The coefficient is not a true constant, but attempts to characterize the departure of reflectance from that of a Lambertian surface (i.e., isotropic reflectance). A k value of 1 indicates isotropic 
reflectance. A lower coefficient represents departure from isotropic reflectance and represents the degree of anistrophy. It is also important to note that $k$ is wavelength-dependent. The Minnaert constant was calculated using least-squares regression on the variables $\mathrm{x}$ and $\mathrm{y}$, where $x=\log (\cos i \cos e)$ and $y=\log (L \lambda \cos e)$. The slope of the regression equation represents $k$.

One way to evaluate the Minnaert-correction procedure is to compute a global $k$ value for an image. This approach assumes that the anisotropic nature of reflectance is homogeneous over the study area. This assumption is known to be invalid as topographic and land-cover variation will causek to vary spatially, such that a global value may not produce spatially consistent normalization results. Numerous investigators, however, have indicated that this approach can reduce the "topographic effect" in satellite imagery.

It is reasonable to assume that land cover exhibits a strong influence on anisotropic reflectance such that $\mathrm{k}$ should be computed for land-cover classes. To test this, an image segmentation approach was investigated. The fundamental land-cover structure within the scene was produced using NIR image thresholding and the ISODATA clustering algorithm on a NIR/RED ratio image. This resulted in a land-cover map (three classes) for Nanga Parbat.

Snow, vegetation, and nonvegetation features were easily mapped as these land-cover classes are known to exhibit different anisotropic-reflectance characteristics [Hugli and Frei, 1983]. The purpose of the classification is not to accurately map these features, but to segment the image into regions so that three $\mathrm{k}$ values can be computed that characterize the influence of land cover on anisotropic reflectance.

We tested these procedures on the near-infrared image because the influence of topography on the direct irradiance is evident (Fig. 1). We also performed two-dimensional semivariogram analysis on several $100 \times 100$ pixel subsections to compare the spectral variance of original and normalized imagery (Fig. 2). The locations for testing were selected on the basis of homogeneous land cover. Effective topographic normalization should result in decreased spectral variance (lower semivariance values). 


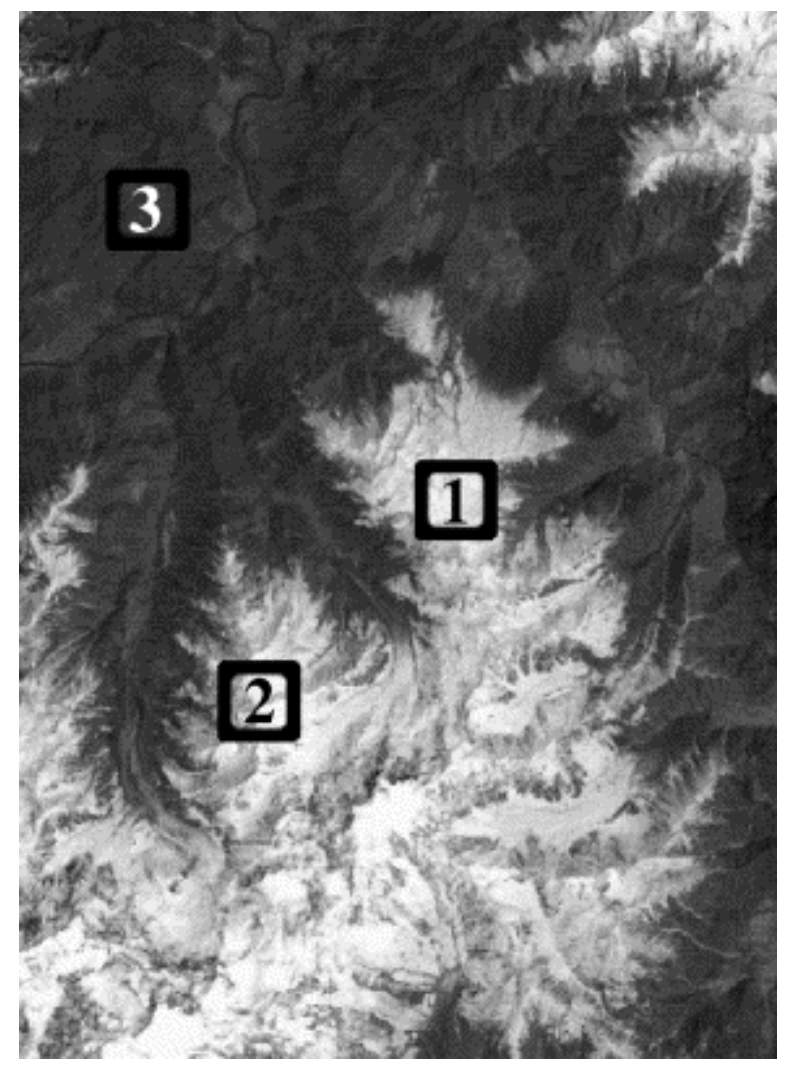

Fig. 2. SPOT 3 ortho-rectified NIR image depicting sample locations for scatterplots and two-dimensional semivariogram analysis. Each sample location represents a $100 \times 100$ pixel area of relatively homogeneous land cover.

\section{Typographic analysis}

The $7 \mathrm{~km}$ of vertical relief of the Nanga Parbat massif produces exceptionally strong orographic and gravitative energy gradients that are responsible for much geomorphic work by the different processes. We differentiate five geomorphic-process zones on the northern slopes of Nanga Parbat that reflect temporal and spatial differences in lithology, structure, and process: (i) a lowermost zone of fault scarps and river incision; (ii) a zone of past glacial erosion and deposition; (iii) a lower zone of superimposed past and modern-day warm-based ice; (iv) an upper zone of superimposed past and modern-day, warm-based ice; and ( $\mathrm{v}$ ) a high-altitude zone of glacier erosion (equilibrium line altitude (ELA)/paleoELA-based), cold-based ice.

We systematically sampled these zones on the north side of Nanga Parbat (Fig. 3). We specifically limited the extent of the DEM subarea in the east-west direction so that statistical characterization along a north-south profile might show variations related to surface processes and erosion with altitude. In order to conduct one- and two-dimensional analyses of the relief along this profile, each zone was of equal size $(\sim 10 \times 4 \mathrm{~km})$. 

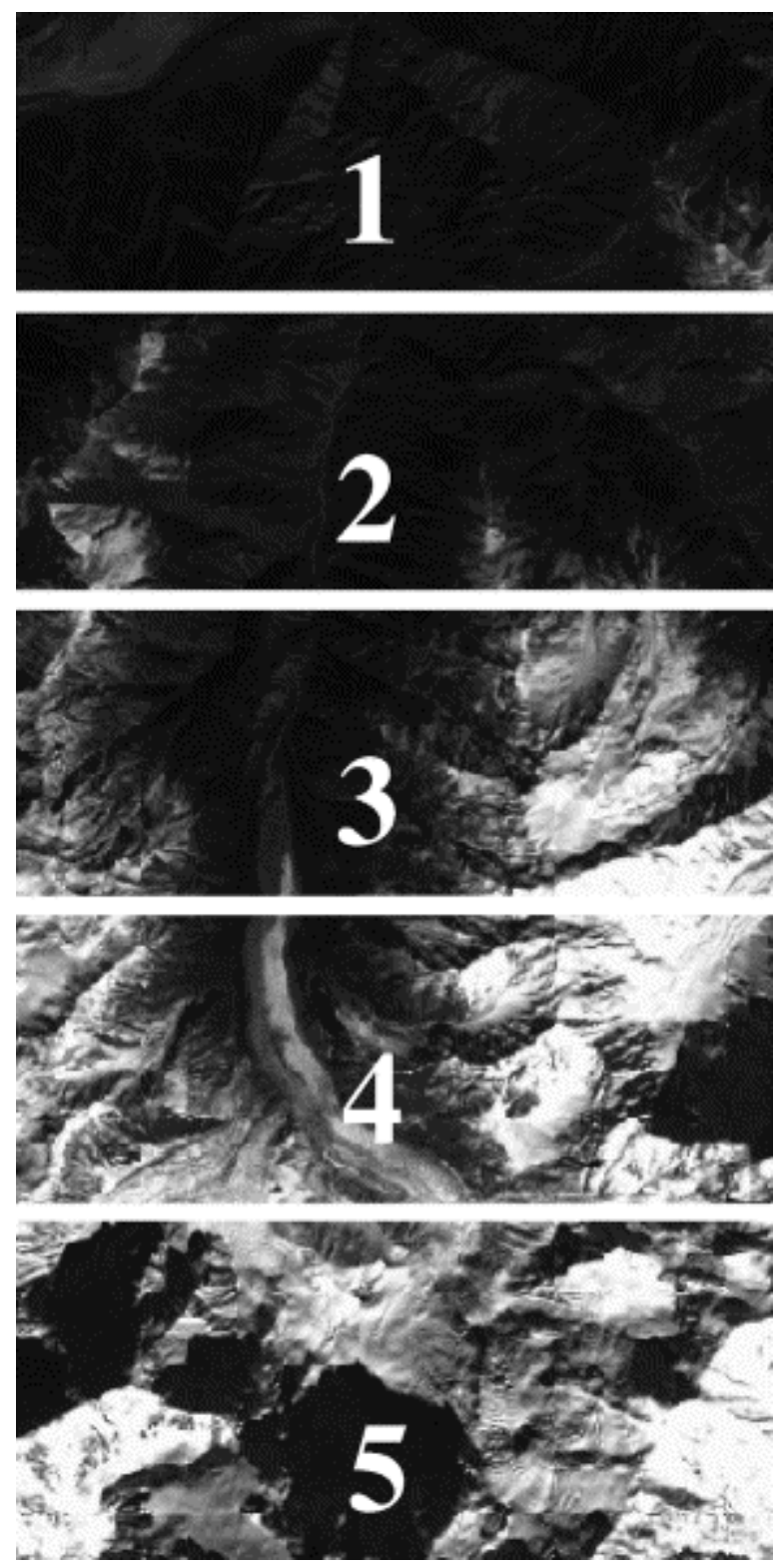

Fig. 3. SPOT 3 ortho-rectified panchromatic image of the digital elevation model subarea that was used for analysis of the topography.

Relief statistics were calculated for east-west swaths across the DEM subarea over a 10-km distance. This equates to calculating statistics for altitude for every row of our DEM subarea, using every column of that row. This analysis enables the production of an aggregate northsouth profile where we examine how the relief varies as a function of surface processes.

Similarly, we examined the scale-dependent characteristics of the topography in relation to surface processes. We conducted one-dimensional semivariogram analysis of each row, where the average semivariance $\left(\overline{\mathrm{S}}^{2}\right)$ is computed as follows: 


$$
\bar{S}^{2}(h)=\frac{1}{2} m \sum_{i=1}^{m}\left(z_{i}-z_{i+k}\right)^{2}
$$

where $z$ is the altitude from a single grid cell, $h$ represents the sampling lag distance, and $m$ is the number of sampled pairs per lag. This analysis resulted in the production of a semivariogram for each row of the DEM subarea. By selecting a particular lag distance, a northsouth profile of the semivariance can be examined.

We recognize that this approach characterizes the relief in an east-west direction, and that twodimensional analysis is required to accurately characterize the topography. Results from summary statistics clearly depicted erosion-process zones. Consequently, we conducted twodimensional semivariogram analysis for each zone, where every grid cell was compared to every other grid cell within each zone. Within an $n_{x} \times n_{y}$ grid there will be $N$ point pairs, where $\mathrm{N}=n_{x}{ }^{2}\left(n_{y}{ }^{2}-1\right) / 2$. The variance component is $\Delta z=\left(z_{1}-z_{2}\right)^{2}$, and the horizontal distance is $\Delta x=\left[\left(x_{1}-x_{2}\right)^{2}+\left(y_{1}-y_{2}\right)^{2}\right]^{0.5}$. The variance was summed over a binned horizontal distance interval $(20 \mathrm{~m})$ and divided by the number of observations within each bin to calculate the average semivariance $\left(\overline{\mathrm{S}}^{2}\right)$.

Our spatial analysis on the north side of Nanga Parbat is not spatially constrained to the Raikot basin. Basin analysis is a very popular approach that can be used to assess relief characteristics. From a geophysical perspective, however, we know that the influence of denudational unloading on tectonic uplift at Nanga Parbat is not spatially constrained at the basin scale and that fluctuations in the influx of mass are dependent upon denudational unloading at the regional scale, which may be spatially constrained by the Raikot and Stak faults [Zeitler et al., 2001a and Zeitler et al., 2001b]. Therefore, scale-dependent relief characteristics may be used to assess surface processes and provide a framework for estimating erosion rates [Bishop and Shroder, 2000].

\section{RESULTS}

\section{Anisotropic-reflectance correction}

Statistical analysis of the original and normalized imagery indicated that the correction methods did not produce acceptable results for all pixels (Table 2). Radiance values were frequently high and not representative of the land-cover classes. This "overcorrection" (extreme radiance values) resulted in an increase in spectral variance in the normalized imagery. 
Table 2. Summary statistics for SPOT 3 NIR image and normalized NIR imagery

\begin{tabular}{|c|c|c|c|c|c|c|}
\hline Image & Min & $\operatorname{Max}$ & Median & Mean & S.D. & Range \\
\hline SPOT 3 NIR & 17.73 & 300.24 & 85393 & 120.95 & 62.51 & 282.51 \\
\hline Cosine correction & 19.70 & $2.48 \times 10^{7}$ & 118.82 & 401.18 & 55958.03 & $2.48 \times 10^{7}$ \\
\hline Minnaert conrection ${ }^{a}$ & 18.69 & 50879 & 90.42 & 128.64 & 144.66 & 50860.31 \\
\hline Minnaert conrection & 17.95 & 26399 & 78.22 & 123.19 & 86.62 & 26381.05 \\
\hline
\end{tabular}

The Cosine-correction method did not effectively normalize the SPOT NIR image (Fig. 4). Extreme radiance values exist where steep slopes reduce the magnitude of the direct irradiance, such that the magnitude of cos i values do not accurately estimate the magnitude of the irradiance at the surface. This is demonstrated in Fig. 5, where we sampled a homogeneous land-cover class (snow) and plotted the relationship between normalized radiance and cos $\mathrm{i}$. The nonlinear relationship is the result of steep slopes that receive additional irradiance from the diffuse-skylight and adjacent-terrain irradiance components.

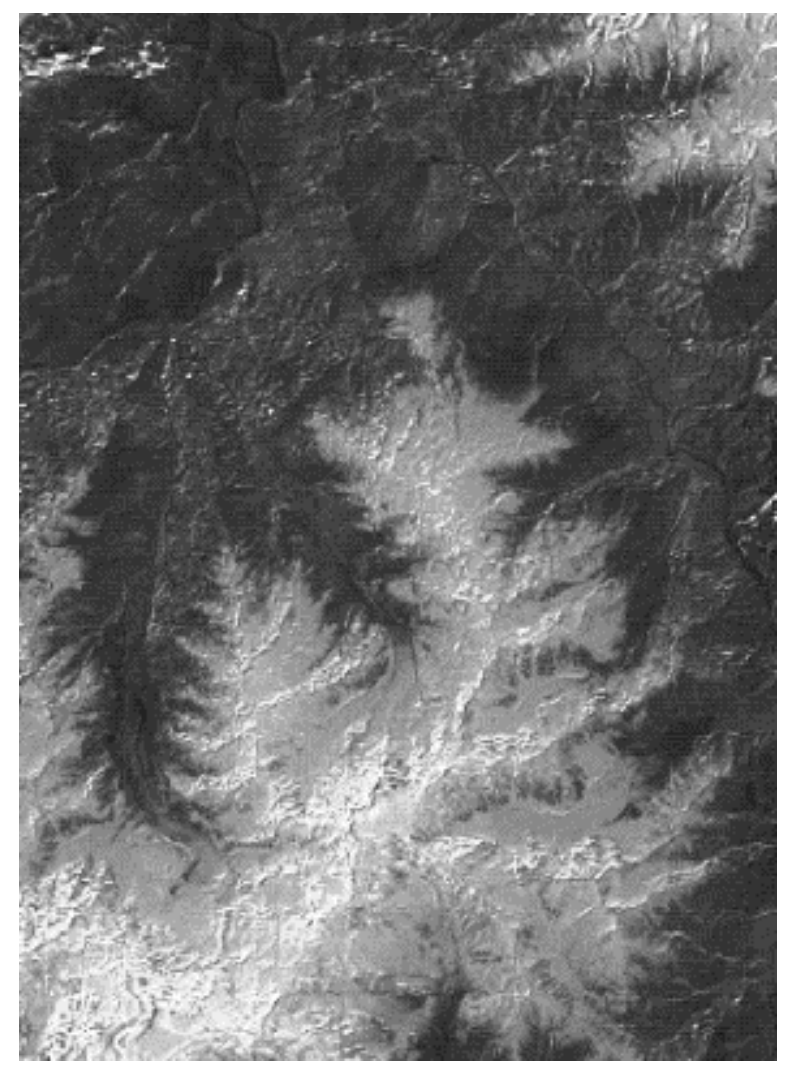

Fig. 4. Normalized SPOT 3 NIR image using the Cosine-correction method. Extreme radiance values are found throughout the image. 


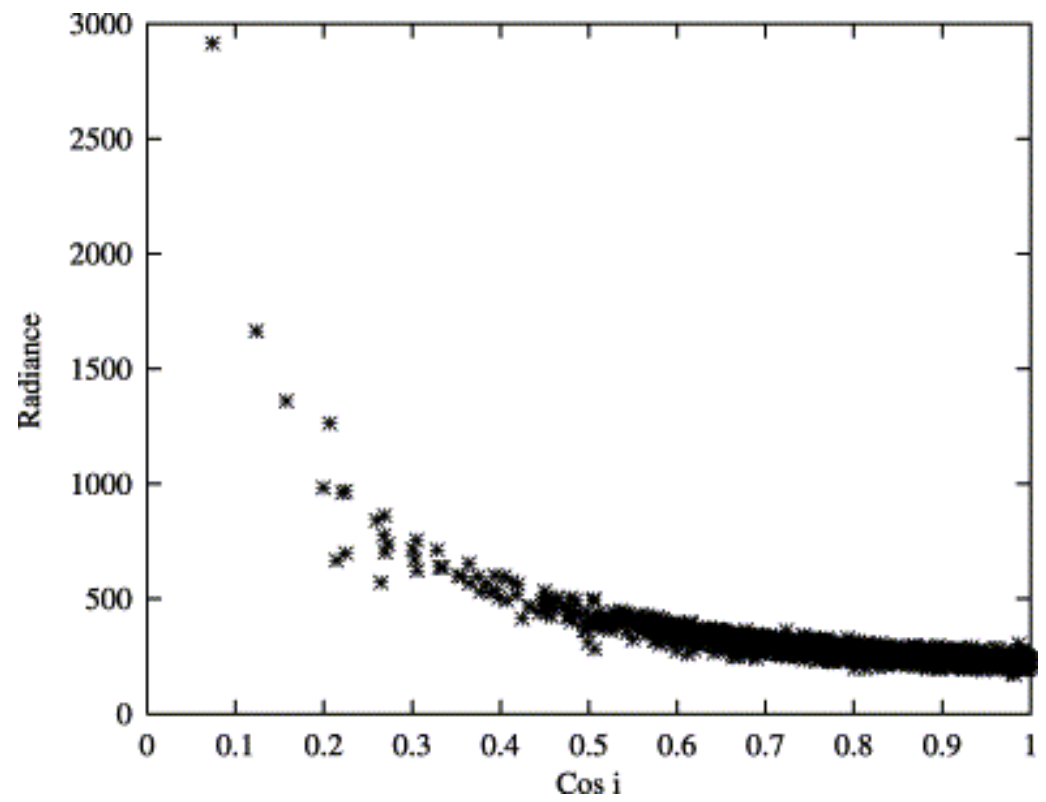

Fig. 5. Scatterplot of normalized (Cosine-correction method) NIR radiance and cos i for sample location 2 in Fig. 2. The method "overcorrects" and produces extreme radiance values where steep slopes angles reduce the direct solar irradiance.

Results from the Minnaert-correction method (globally computed $k$ ) yielded a Minnaert constant and $r^{2}$ value of 0.5234 and 0.123 , respectively. Statistical analysis and visual interpretation indicated that the influence of topography was reduced, although high radiance values were found at the base of steep slopes (Fig. 6). Similar to Cosine-correction results, we found a nonlinear relationship between normalized radiance values and cos $i$ (Fig. 7). Semivariogram analysis revealed that the local spectral variance was dramatically reduced over snow-covered portions of the landscape (Fig. 8), even though the $k$ value does not uniquely characterize the influence of snow/firn and topography on surface radiance (low $\left.r^{2}\right)$. These results indicate that a globally derived Minnaert constant does not characterize the relationship between topography, land cover and surface radiance in complex scenes exhibiting multiple land-cover classes. It does, however, demonstrate the potential of the method if multiple Minnaert constants can be computed with high $r^{2}$ values. 


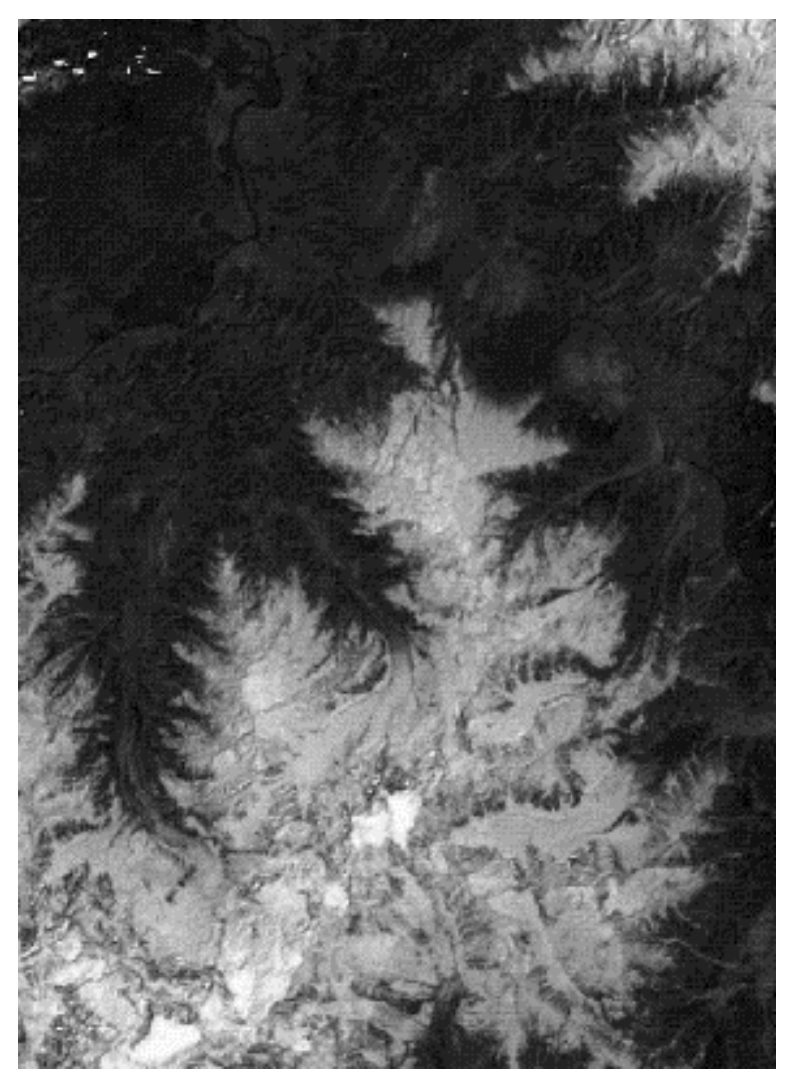

Fig. 6. Normalized SPOT 3 NIR image using the Minnaert-correction method (globally computed k). Spectral variance visually appears to be reduced, however, extreme radiance values are found at the base of steep slopes.

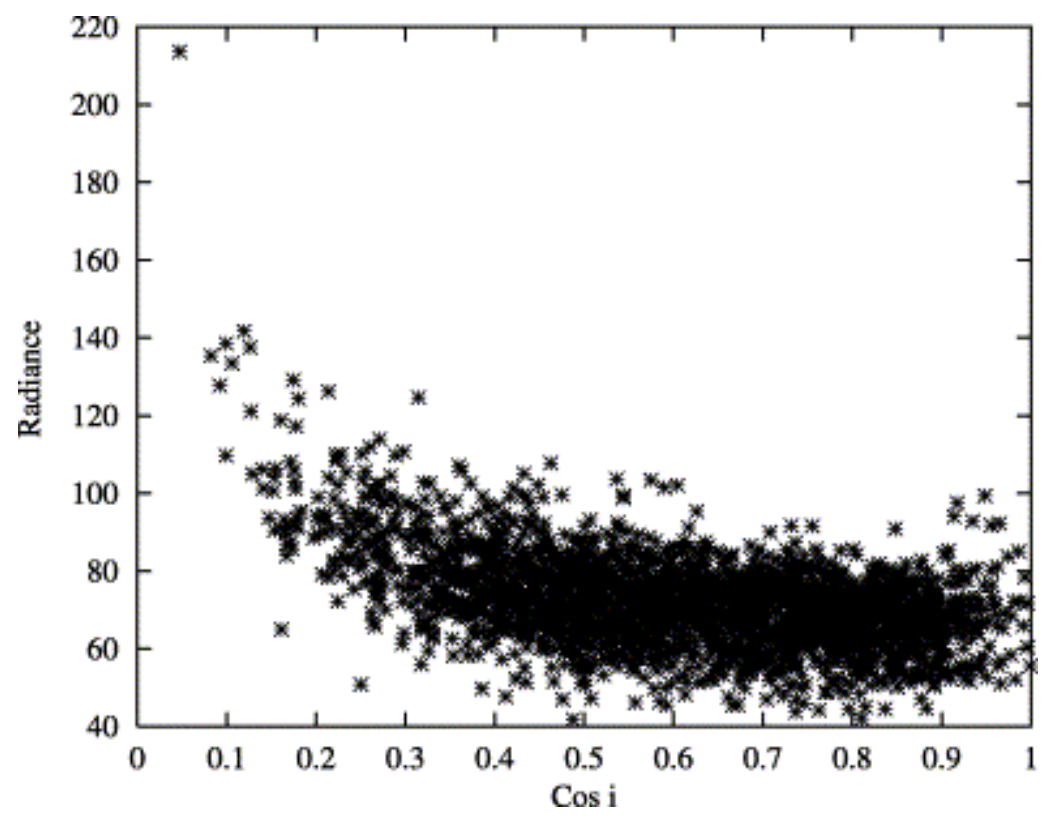

Fig. 7. Scatterplot of normalized NIR radiance (Minnaert-correction method and globally computed k) and cos i for sample location 3 in Fig. 2. The method "overcorrects" and produces relatively high radiance values. 


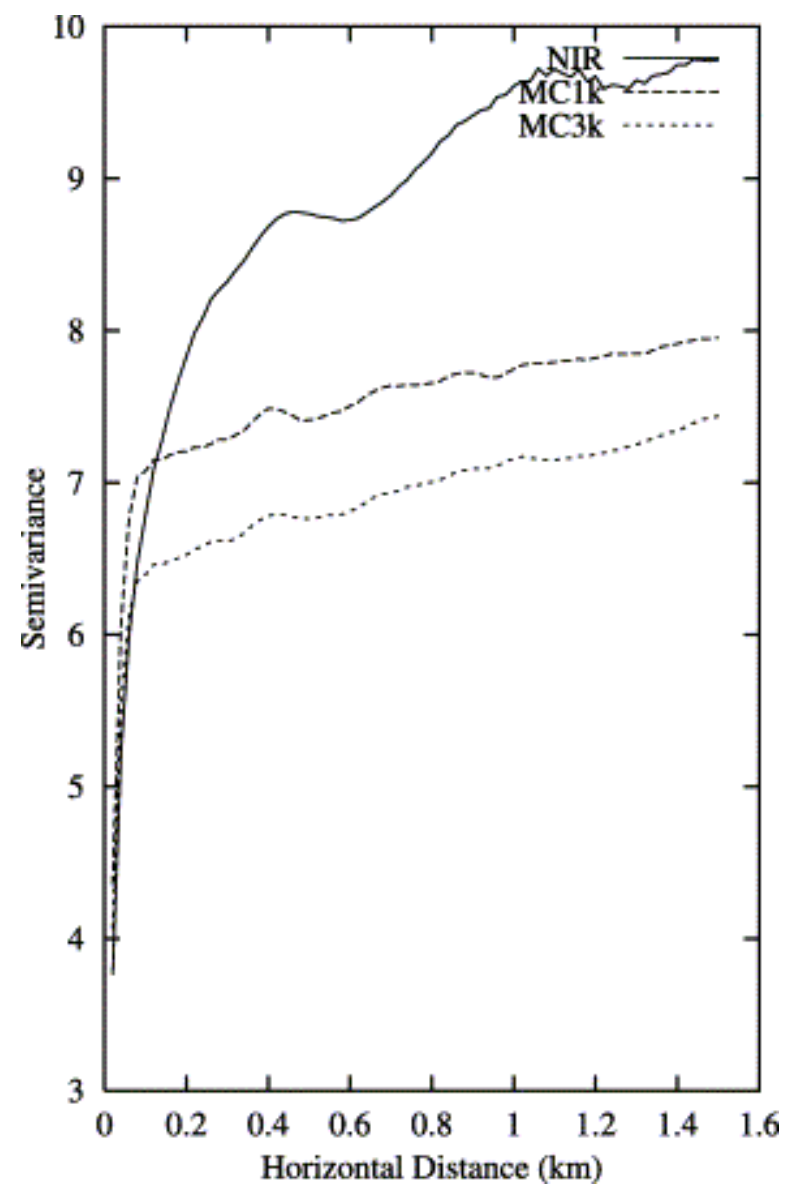

Fig. 8. Semivariograms from sample location 1 in Fig. 2 depicting the spectral variance in the original NIR image (NIR), Minnaert-corrected NIR image using a globally computed k (MC1k), and Minnaert-corrected NIR image using land cover-computed k's (MC3k). A greater reduction in the "topographic effect" results from using multiple $\mathrm{k}$ values.

Results from the Minnaert-correction method (land-cover computed $k$ 's) indicated that it is possible to produce multiple $k$ values that reasonably characterize the influence of land cover and topography on reflectance (Table 3). The normalized image is visually similar to Fig. 6 , however, this implementation reduced spectral variance better than the other methods over the entire image (Table 2) and for homogeneous land-cover classes (Fig. 8). The decrease in semivariance represents a decrease in spectral variation caused by the topography.

Table 3. Results of land-cover stratified regression analysis

\begin{tabular}{lrrr}
\hline Class & $k$ & \multicolumn{1}{c}{$1^{2}$} & \multicolumn{1}{l}{$n$} \\
\hline Nonvegetation & 0.4052 & 0.4081 & 1266086 \\
Vegetation & 0.4437 & 0.5182 & 418362 \\
Snow/fim & 0.4840 & 0.5757 & 958465 \\
\hline
\end{tabular}




\section{Topographic relief}

Swath profile analysis revealed the extreme relief on the northern side of Nanga Parbat (Fig. 9). In general, the altitude systematically increases towards the south, although three distinct altitude trends can be identified based upon the average rate of change in altitude. These trends represent (i) the lower altitude Raikot fault zone, which exhibits steep slopes and V-shaped valleys transverse to the fault; (ii) intermediate altitudes where past and modern, warm-based glacier erosion and deposition has significantly altered the landscape; and (iii) an upper region where cold-based and protective glaciation dominates.

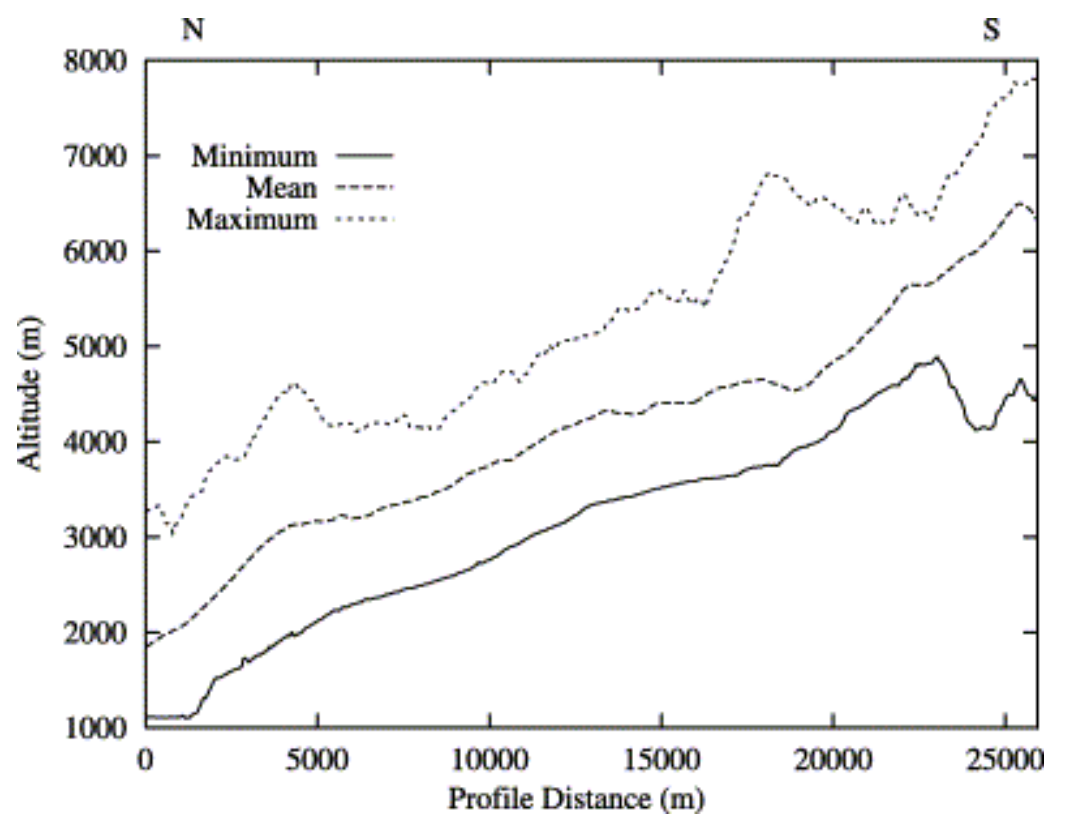

Fig. 9. Swath profile of the altitude on the northern side of Nanga Parbat.

The relief profile provides additional insight into the nature of surface processes that erode the landscape (Fig. 10). In the Raikot Fault zone (0-5 km profile range), rapid river incision produced deep gorges that exhibit strath terraces caused by rapid river incision. The relief in this area systematically increases to a maximum of $\sim 2600 \mathrm{~m}$ at the southernmost boundary of the fault zone. The maximum relief then decreases, as the influence of past glaciation alters the topography. 


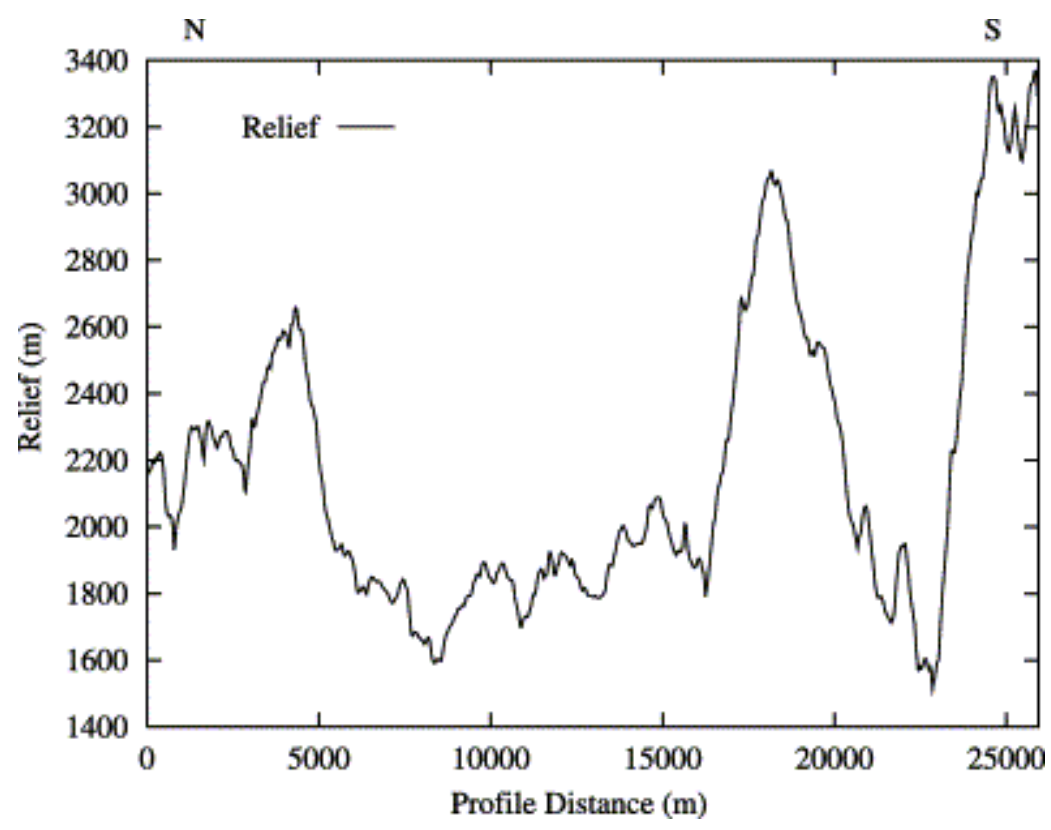

Fig. 10. Swath profile of the relief on the northern side of Nanga Parbat. The decrease in relief at $\sim 20-23$ $\mathrm{km}$ is the result of the sampling design, such that the metric does not effectively characterize relief for comparison purposes.

This rapid decrease in relief is associated with a monsoon-driven glacial event that occurred approximately $65 \mathrm{~K}$ year $^{-1}$ [Phillips et al., 2000]. At this time, glaciation covered most of the landscape. Farther along the profile at intermediate altitudes, the collective influence of glaciation accounts for the relatively low maximum relief conditions ( $\sim 1800 \mathrm{~m})$. Farther south at higher altitudes, the maximum relief systematically increases, indicating the erosive nature of temperate alpine glaciers. At a profile distance of $\sim 17$ and $24 \mathrm{~km}$, deep glacier valley erosion is associated with $\sim 3.1$ and $3.4 \mathrm{~km}$ of relief, respectively. The decrease in relief portrayed in Fig. 10 at a profile distance of $\sim 20-23 \mathrm{~km}$ is the result of the orientation of transects with respect to the orientation of the knife-edge ridge (i.e., orientations of the transects and the ridge are nearly equivalent, so that the relief decreases).

Examination of the variation in altitude along the profile also characterizes the role of past and modern glaciation on the landscape hypsometry (Fig. 11). An increase in variability in altitude would be expected where active river incision and recent uplift produce steep slopes and extreme relief. As the current influence of these processes decrease to the south along the profile, and the landscape begins to record the influence of past glaciations, we see a sharp decrease in variability. The start of this decline coincides exactly where the Bezar Gali glacial erosion surface occurs. Furthermore, as modern glacial processes leave an imprint on the topography, the variability along the profile increases, such that a local variability maximum is associated with the location of modern-day alpine glaciers. These results initially suggest that glaciation plays an important role in mesocale relief production. 


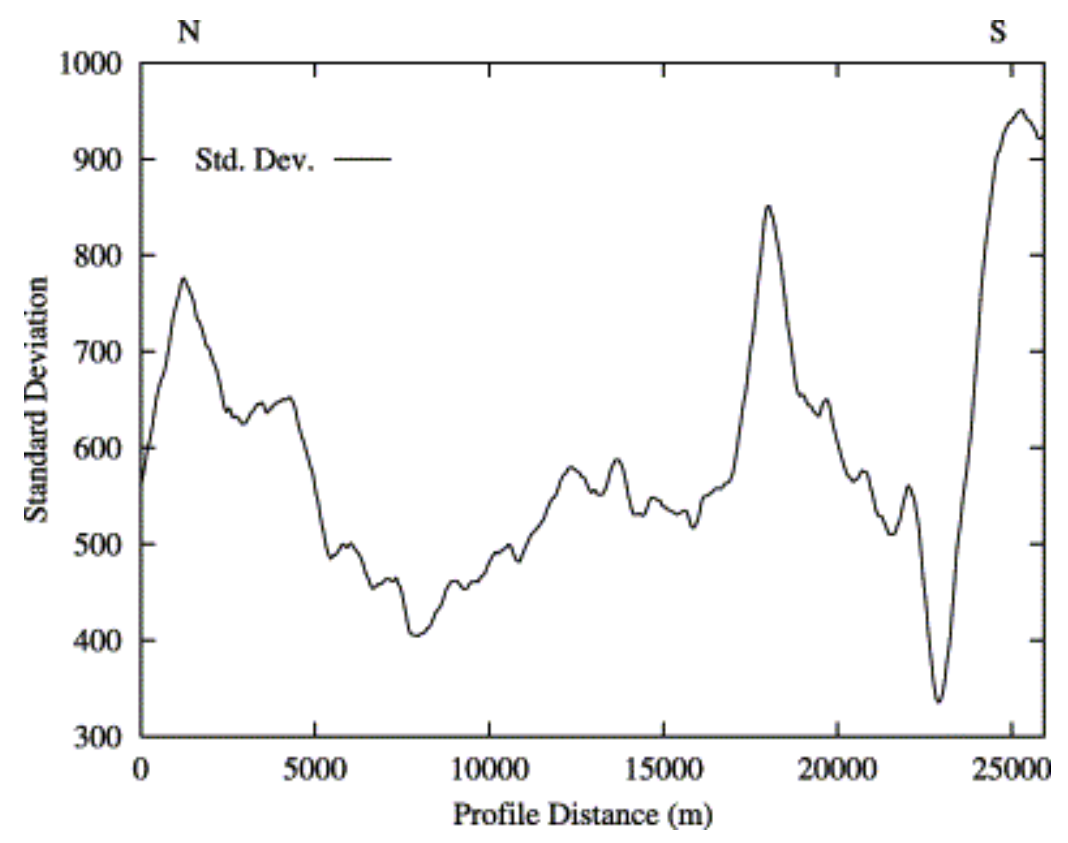

Fig. 11. Swath profile of the variability of altitude on the northern side of Nanga Parbat. The decrease in the variability at $\sim 20-23 \mathrm{~km}$ is the result of the sampling design, such that the metric does not effectively characterize variability for comparison purposes.

It is problematic to make conclusions based upon the use of first-order statistics that do not account for the scale-dependent nature of relief. One-dimensional semivariogram analysis revealed that at lag distances $\leq 1 \mathrm{~km}$, the maximum relief on the landscape is associated with active river incision in the Raikot fault zone and at the highest altitudes where tectonic uplift and multiple glaciations are responsible for extreme relief (Fig. 12). At intermediate altitudes, a systematic decrease in $\sqrt{\bar{S}^{2}}$ values (relief) is caused by glacier erosion and redistribution of sediment. This result suggests that as modern glaciation dominates the landscape at intermediate altitudes, glacial processes operating at this scale do not produce extreme relief. We might expect this result as river incision operates at a very different scale compared to glaciation on the north side of Nanga Parbat. Warm-based glaciers are known to be an effective erosion agent; therefore, if they are capable of producing extreme relief, we must examine altitude differences at greater distances that represent the operational scale of glacier erosion. 


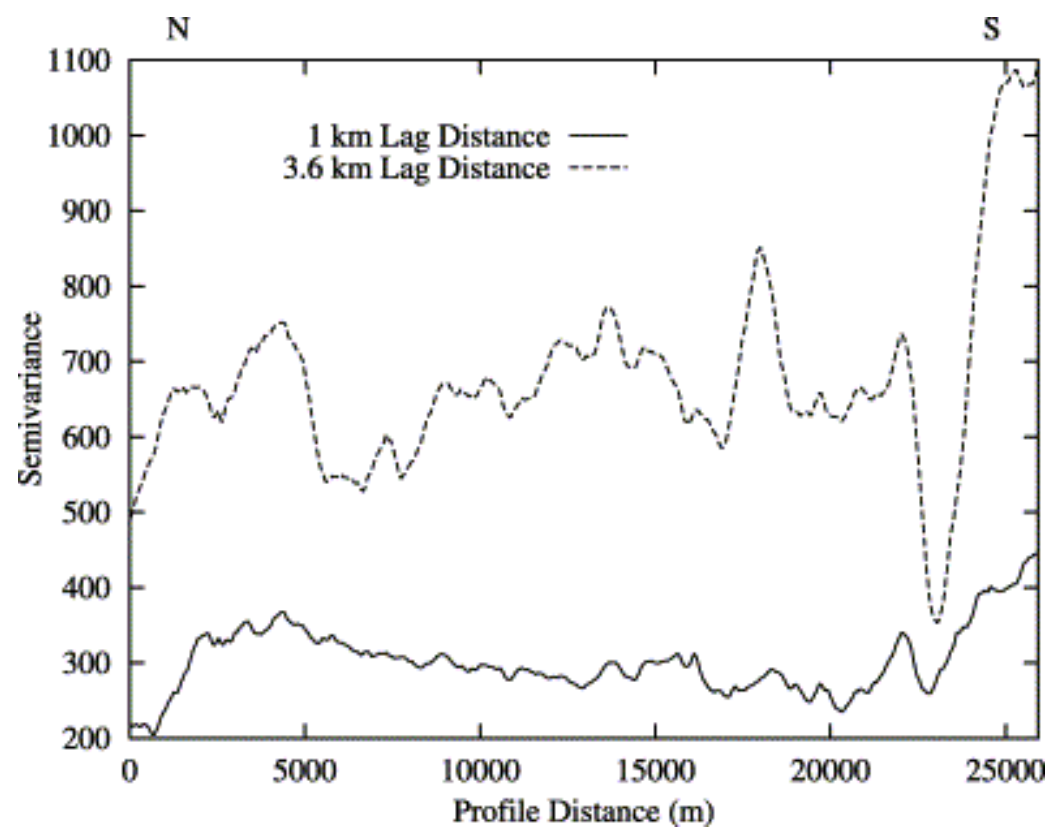

Fig. 12. Swath profile of the semivariance at two lag distances on the northern side of Nanga Parbat. The decrease in semivariance at $\sim 23 \mathrm{~km}$ is the result of the sampling design, such that the metric does not effectively characterize relief for comparison purposes.

Results of semivariogram analysis for lag distances $\geq 2.5 \mathrm{~km}$ indicated that glaciation can produce comparable, if not greater mesoscale relief than processes of river incision and slopefailure (Fig. 12; 3.6-km lag distance is most representative of extreme relief). Periodic fluctuations in $\sqrt{\bar{S}^{2}}$ values at $3.6 \mathrm{~km}$ lag distance reflect the overprinting of glacial events along the profile caused by glaciation at intermediate and high altitudes. The localized maximum peaks of $\sqrt{\bar{S}^{2}}$ values at the profile distances of $\sim 14$ and $17 \mathrm{~km}$ (Fig. 12) are approximately associated with the ELA zones of the Buldar and Raikot glaciers, respectively. The maximum relief, at a profile distance of $24 \mathrm{~km}$, is the result of glacier erosion at lower altitudes closer to the ELA zones on both sides of the main Nanga Parbat ridge. If we take into consideration the depth of glacier ice in the ELA zones, the relief is greater than what our analysis of topography presents.

We compare these results to two-dimensional analysis before making conclusions. In the tectonically active Raikot Fault zone, surface processes are actively adjusting to tectonic forcing [Bishop et al., 2002], producing a considerable amount of relief in zone 1 (Fig. 13). At intermediate altitudes (zones 2-4), $\sqrt{\bar{S}^{2}}$ values generally decrease at all lag distances. Zone 5 exhibits the greatest $\sqrt{\bar{S}^{2}}$ values at all lag distances. These results suggest that the product of glaciation at intermediate altitudes is one of decreasing relief and an overall leveling of the landscape. This can be clearly seen in the middle of Fig. 14 . 


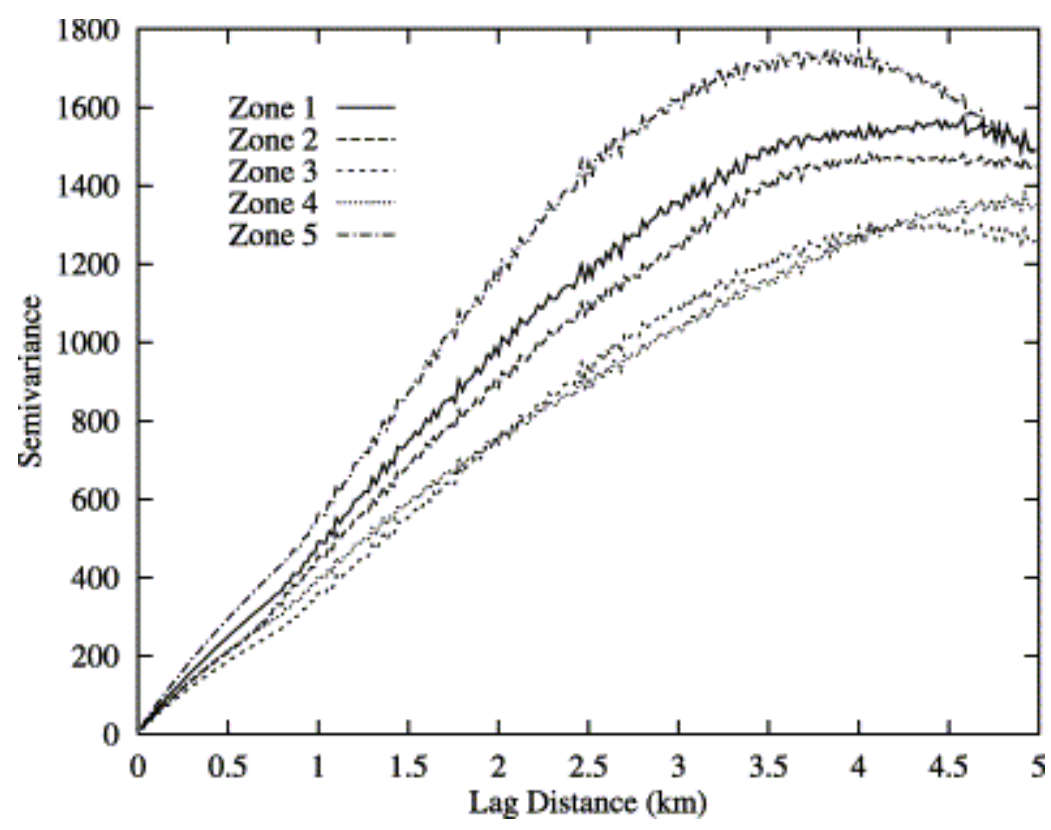

Fig. 13. Semivariograms for different surface process zones on the northern side of Nanga Parbat. Each semivariogram was computed by comparing the altitude of every pixel in a zone. Zone 1 is a lowermost zone of fault scarps and river incision. Zone 2 represents a zone of past glacial erosion and deposition. Zone 3 is the lowermost zone of superimposed past and modern-day warm-based ice. Zone 4 is the uppermost zone of superimposed past and modern-day warm-based ice. Zone 5 represents the high altitude zone of glacier erosion (ELA/paleoELA-based), cold-based ice. 


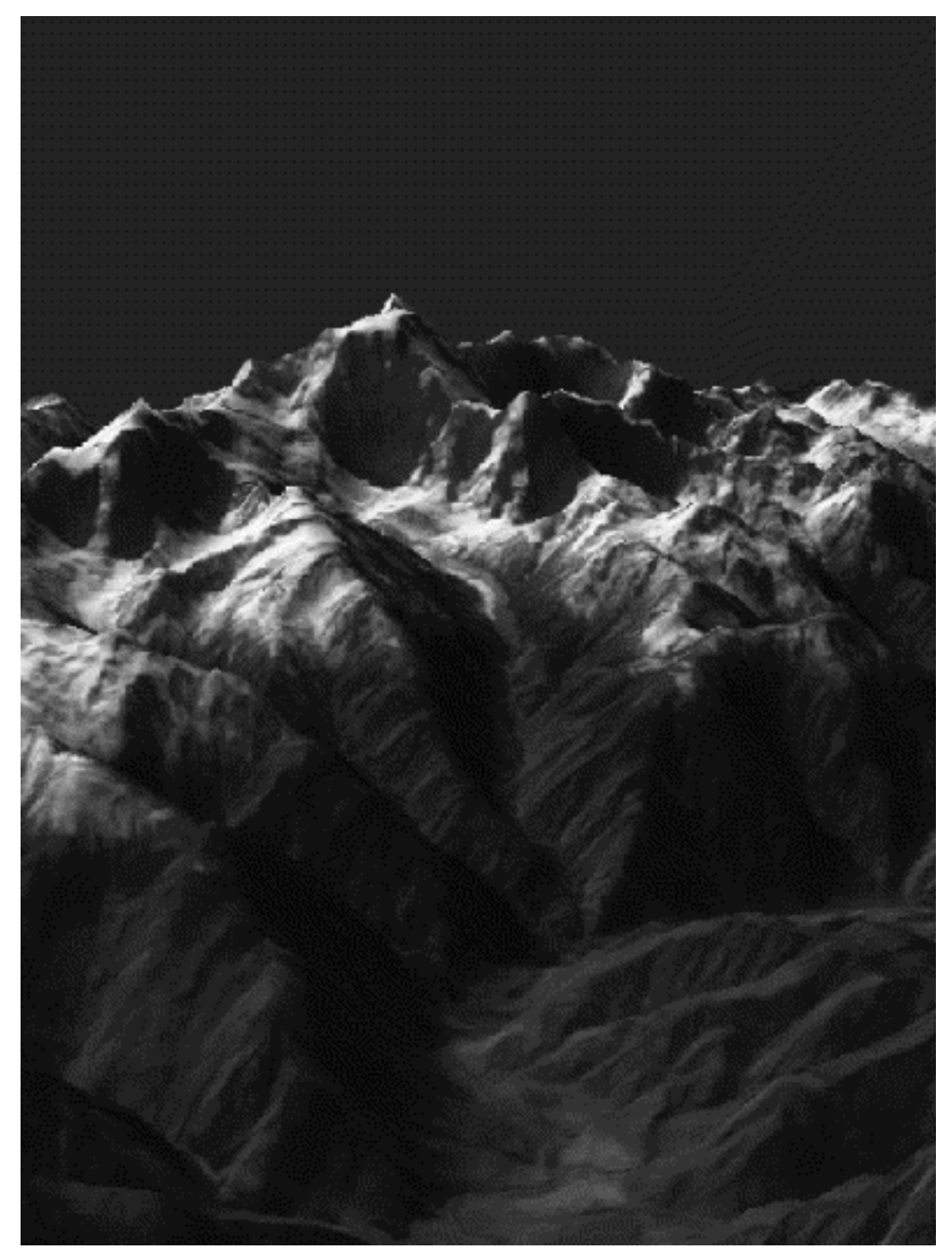

Fig. 14. SPOT 3 false-color composite image draped over the digital elevation model. The 3-D perspective view is from the north looking south at Nanga Parbat. The Raikot basin is in the center of the scene. Vertical exaggeration is $2 \times$ to visually enhance mesoscale relief and display the leveling of the topography by glaciation at intermediate altitudes.

\section{DISCUSSION}

Geoscientists have predominantly used qualitative methods to extract geomorphological information from satellite imagery. Scientific visualization techniques can be used to examine two- and three-dimensional perspectives, thus providing important spatial information about geomorphic features and events (e.g., high-altitude erosion surfaces, glaciers, lacustrine deposits, catastrophic floods) and the topography. Quantitative information about surficial materials and landforms is difficult to obtain due to complex radiation transfer processes involving the atmosphere and topography. 
Our radiometric calibration results indicate that it is possible to significantly reduce the spectral variation in imagery using the Minnaert-correction method, although numerous issues remain. Our simplistic procedure of image-segmentation to generate accurate $\mathrm{k}$ values is problematic because it initially requires land-cover information. [Colby, 1991] indicated that locally computed k's may have value in reducing the "topographic effect" by accounting for local land-cover conditions.

Our results also indicate that the calibration problem is not limited to the computation of accurate $\mathrm{k}$ values. Extreme radiance values are the result of inadequate modeling of the irradiance as cos i does not account for cast shadows and the diffuse-skylight and adjacentterrain irradiance. These radiation transfer processes are highly scale-dependent and hemispherical topographic analysis is required to account for their varying influence over the landscape. Consequently, this semi-empirical radiation transfer model requires additional topographic parameters to account for complex atmosphere-topography, radiation interactions. The development of improved radiation-transfer models will be valuable in remote sensing and geomorphology studies, and will enable the investigation of the spatial distribution of climate forcing on surface processes (e.g., snowmelt, runoff, ablation) and erosion.

Nanga Parbat has undergone extreme environmental change over a very short period of geological time [Shroder and Bishop, 2000 and Bishop et al., 2002]. [Bishop et al., 2002] have shown that glacial, fluvial and slope processes all play important roles at different times, and that they can do so sequentially on the same portion of the landscape. Investigators have attempted to characterize the individual roles of river incision and glaciation in relief production [Burbank et al., 1996, Brozovik et al., 1997. N. Brozovik, D.W. Burbank and A.J. Meigs, Climatic limits on landscape development in the northwestern Himalaya. Science 276 (1997), pp. 571574.Brozovik et al., 1997, Whipple and Tucker, 1999, Brocklehurst, 2002 and Finlayson et al., 2002]. These studies and others have provided us with a better understanding of river incision, glaciation, and modern process rates. The influence of glaciation on the unloading history of the massif, however, is still relatively unknown. We know that the major valleys, including the Indus, have undergone extensive and periodic glaciation [Shroder et al., 1989]. Similarly, systematic and catastrophic geomorphic events are also responsible for the denudational unloading. Therefore, modern-day river or glacier incision rates alone cannot be applied over millions of years to characterize denudational unloading at Nanga Parbat.

The influence of glacial erosion on the relief structure of the landscape is an important question. Our results for intermediate altitudes concur with [Brozovik et al., 1997], indicating that glaciation can limit relief up to some altitude near the equilibrium line altitude (ELA). Our results also indicate that glaciation can produce greater mesoscale relief than river incision, as glaciation in concert with uplift is primarily responsible for relief production at high altitudes. Given the temporal and spatial fluctuations of surface processes in topographic evolution, it is difficult to precisely determine the degree to which river incision and alpine glaciation erode the landscape and produce relief.

At intermediate to higher altitude, deep valley glacier erosion and headwall erosion can effectively remove rock and sediment, while protective cold-based ice on the highest peaks 
permits ridge and peak formation. Consequently, in high mountain environments, glaciation directly and indirectly alters the relief structure of the landscape differently with altitude. These differences can be attributed to the degree of temporal overprinting and spatial overlap of glacial events, such that at intermediate altitudes, the degree of spatial overlap is less than at high altitudes. More research into providing a more detailed explanation of this differential influence of glaciation on topography is required.

A challenge will be to develop better approaches that can be used to relate the properties of topography to the magnitude of erosion [Howard, 1996 and Small, 1999]. Currently, there is no widely acceptable method of such estimation, and scientists would like to use DEMs to estimate erosion rates provided that geomorphometric properties can be calibrated with measured rates. Our results indicate that the topography does contain information/patterns that reflect changes in erosion processes with altitude. We speculate that calibration will be difficult to achieve without characterizing variations in the topography that represent the spatial constraints for surface processes. More geomorphometry research that addresses the modeling and analysis of the hierarchical organization of topography may provide new insights.

To many, it may not appear that radiation transfer and geomorphometry are related research topics for understanding relief production. Both, however, are important for studying surface processes and erosion. For example, complex radiation transfer processes that include atmosphere-topography interactions govern the radiation budget. Radiative forcing directly and indirectly affects glacial ablation, meltwater production, the generation of fluvial and glacial landforms, and ultimately denudation and relief production. If erosion models are to accurately simulate topographic evolution, glacier mass balance and glacial erosion must be taken into consideration. Currently, the multi-scale topographic effects on glacier mass balance are not always considered. Topographic, solar-radiation, transfer models can be used to study radiative forcing on surface processes. Similarly, solving the anisotropic-reflectance correction problem will enable object-oriented landform analysis, such that topographic information from DEMs can be integrated with image information to examine the spatial and contextual relationships between landforms. Such multidisciplinary research involving remote sensing science and geomorphology should provide new information regarding surface processes, erosion, and relief production.

\section{CONCLUSIONS}

Remote sensing and geomorphometry provide new opportunities to study mountain environments and relief production. Satellite imagery must be radiometrically calibrated to account for atmospheric and topographic effects. Our results indicate that the "topographic effect" in satellite imagery can be reduced using the Minnaert-correction method, although extreme radiance values are the result of the model's inability to account for the diffuse-skylight and adjacent-terrain irradiance. Additional topographic analysis and parameterizations that characterize complex atmosphere-topography radiation interactions are required. Such new parameterizations are needed to improve information extraction from satellite imagery, and in geomorphological studies to investigate microclimate, surface runoff, and glacial processes 
which influence erosion and relief production. Our topographic analysis revealed that the relief structure at Nanga Parbat is spatially variable and correlated to geomorphic events and dominant surface processes. River incision and glaciation are both responsible for relief production at Nanga Parbat, although our results show that glaciation generates the greatest mesoscale relief at high altitudes. At intermediate altitudes, warm-based glaciation was found to decrease relief. These results indicate that glaciation can have a differential influence on the relief structure of the landscape. More research is required to develop and formalize a spatiotemporal theory on mountain topographic organization so that geomorphometric parameters can be used to estimate erosion rates. This will require spatial and temporal information acquired from satellite imagery and DEMs.

\section{ACKNOWLEDGMENTS}

This work was funded by the University Committee on Research at the University of Nebraska at Omaha and the National Science Foundation (grant no. EAR 9418839 and EPS-9720643).

\section{REFERENCES}

Avouac and Burov, 1996. J.P. Avouac and E.B. Burov, Erosion as a driving mechanism of intracontinental mountain growth. Journal of Geophysical Research 101 (1996), pp. 747-769.

Bishop and Colby, 2002. M.P. Bishop and J.D. Colby, Anisotropic reflectance correction of SPOT-3 HRV imagery. International Journal of Remote Sensing 2310 (2002), pp. 219-222.

Bishop and Shroder, 2000. M.P. Bishop and J.F. Shroder, Jr., Remote sensing and geomorphometric assessment of topographic complexity and erosion dynamics in the Nanga Parbat massif. In: M.A. Khan, P.J. Treloar, M.P. Searle and M.Q. Jan, Editors, Tectonics of the Nanga Parbat Syntaxis and the Western Himalaya (2000), pp. 181-200.

Bishop et al., 1998a. M.P. Bishop, J.F. Shroder, Jr., B.L. Hickman and L. Copland, Scale dependent analysis of satellite imagery for characterization of glacier surfaces in the Karakoram Himalaya. Geomorphology 21 (1998), pp. 217-232.

Bishop et al., 1998b. M.P. Bishop, J.F. Shroder, Jr., V.F. Sloan, L. Copland and J.D. Colby, Remote sensing and GIS technology for studying lithospheric processes in a mountain environment. Geocarto International 134 (1998), pp. 75-87.

Bishop et al., 2002. M.P. Bishop, J.F. Shroder, Jr., R. Bonk and J. Olsenholler, Geomorphic change in high mountains: a western Himalayan perspective. Global and Planetary Change 32 (2002), pp. 311-329.

Brocklehurst, 2002. S.H. Brocklehurst, Glacial erosion and relief production in the Eastern Sierra Nevada, California. Geomorphology 42 (2002), pp. 1-24. 
Brozovik et al., 1997. N. Brozovik, D.W. Burbank and A.J. Meigs, Climatic limits on landscape development in the northwestern Himalaya. Science 276 (1997), pp. 571-574.

Burbank et al., 1996. D. Burbank, J. Leland, E. Fielding, R.S. Anderson, N. Brozovik, M.R. Reid and C. Duncan, Bedrock incision, rock uplift and threshold hillslopes in the northwestern Himalaya. Nature 379 (1996), pp. 505-510.

Chavez, 1996. P.S. Chavez, Jr., Image-based atmospheric corrections-revisited and improved. Photogrammetric Engineering and Remote Sensing 629 (1996), pp. 1025-1036.

Colby, 1991. J.D. Colby, Topographic normalization in rugged terrain. Photogrammetric Engineering and Remote Sensing 575 (1991), pp. 531-537.

Colby and Keating, 1998. J.D. Colby and P.L. Keating, Land cover classification using Landsat TM imagery in the tropical highlands: the influence of anisotropic reflectance. International Journal of Remote Sensing 198 (1998), pp. 1459-1500.

Ekstrand, 1996. S. Ekstrand, Landsat TM-based forest damage assessment: correction for topographic effects. Photogrammetric Engineering and Remote Sensing 622 (1996), pp. 151161.

Finlayson et al., 2002. D.R. Finlayson, D.R. Montgomery and B. Hallet, Spatial coincidence of rapid inferred erosion with young metamorphic massifs in the Himalayas. Geology (2002), pp. 219-222.

Finsterwalder, 1936. Finsterwalder, R., 1936. Carte der Nanga Parbat gruppe (1:50,000). Deutsche Himalaya Expedition 1934.

Howard, 1996. A. Howard, The ephemeral mountains. Science 379 (1996), pp. 488-489.

Hugli and Frei, 1983. H. Hugli and W. Frei, Understanding anistropic reflectance in mountainous terrain. Photogrammetric Engineering and Remote Sensing 495 (1983), pp. 671-683.

Molnar and England, 1990. P. Molnar and P. England, Late Cenozoic uplift of mountain ranges and global climate change: chicken or egg?. Nature 346 (1990), pp. 29-34.

Phillips et al., 2000. W.M. Phillips, V.F. Sloan, J.F. Shroder, Jr., P. Sharma, M.L. Clarke and H.M. Rendell, Asynchronous glaciation at Nanga Parbat, northwestern Himalaya Mountains, Pakistan. Geology 28 (2000), pp. 431-434.

Raymo and Ruddiman, 1992. M.E. Raymo and W.F. Ruddiman, Tectonic forcing of the late Cenozoic climate. Nature 359 (1992), pp. 117-122.

Richter, 1997. R. Richter, Correction of atmosphere and topographic effects for high spatial resolution satellite imagery. International Journal of Remote Sensing 185 (1997), pp. 10991111. 
Schneider et al., 1999. D.A. Schneider, M.A. Edwards, W.S.F. Kidd, M.A. Khan, L. Seeber and P.K. Zeitler, Tectonics of Nanga Parbat, western Himalaya: synkinematic plutonism within the doubly vergent shear zones of a crustal-scale pop-up structure. Geology 27 (1999), pp. 999_ 1002.

Shroder and Bishop, 1998. J.F. Shroder, Jr. and M.P. Bishop, Mass movement in the Himalaya: new insights and research directions. Geomorphology 26 (1998), pp. 13-35.

Shroder and Bishop, 2000. J.F. Shroder, Jr. and M.P. Bishop, Unroofing of the Nanga Parbat Himalaya. In: M.A. Khan, P.J. Treloar, M.P. Searle and M.Q. Jan, Editors, Tectonics of the Nanga Parbat Syntaxis and the Western Himalaya (2000), pp. 163-179.

Shroder et al., 1989. J.F. Shroder, Jr., M.A. Khan, R.D. Lawrence, I.P. Madin and S.E. Higgins, Quaternary glacier chronology and neotectonics in the Himalaya of northern Pakistan. In: L.L. Malinconico and R.J. Lillie, Editors, Tectonics of the Western HimalayasSpecial Paper Geological Society of America vol. 232 (1989), pp. 275-294.

Small, 1999. E. Small, Does global cooling reduce relief?. Nature 401 (1999), pp. 31-33.

Smith et al., 1980. J.A. Smith, T.L. Lin and K.J. Ranson, The Lambertian assumption and Landsat data. Photogrammetric Engineering and Remote Sensing 469 (1980), pp. 1183-1189.

Teillet et al., 1982. P.M. Teillet, B. Guindon and D.G. Goodenough, On the slope-aspect correction of multi-spectral scanner data. Canadian Journal of Remote Sensing 82 (1982), pp. 733-741.

Whipple and Tucker, 1999. K.X. Whipple and G.E. Tucker, Dynamics of the stream-power river incision model: implications for height limits of mountain ranges, landscape response timescales, and research needs. Journal of Geophysical Research 104 (1999), pp. 1766117674.

Zeitler et al., 2001a. P.K. Zeitler, P.O. Koons, M.P. Bishop, C.P. Chamberlain, D. Craw, M.A. Edwards, S. Hamidullah, M.Q. Jan, M.A. Khan, M.U.K. Khattak, W.S.F. Kidd, R.L. Mackie, A.S. Meltzer, S.K. Park, A. Pecher, M.A. Poage, G. Sarker, D.A. Schneider, L. Seeber and J.F. Shroder, Jr., Crustal reworking at Nanga Parbat, Pakistan: metamorphic consequences of thermal-mechanical coupling facilitated by erosion. Tectonics 205 (2001), pp. 712-728.

Zeitler et al., 2001b. P.K. Zeitler, A.S. Meltzer, P.O. Koons, D. Craw, B. Hallet, C.P. Chamberlain, W.S. Kidd, S.K. Park, L. Seeber, M.P. Bishop and J.F. Shroder, Jr., Erosion, Himalayan geodynamics, and the geomorphology of metamorphism. GSA Today 11 (2001), pp. 4-8. 